\title{
Dopamine and serotonin contribute to Paecilomyces hepiali against chronic unpredictable mild stress induced depressive behavior in Sprague Dawley rats
}

\author{
JUAN WANG ${ }^{1,2}$, YANGE LIU ${ }^{1}$, LANZHOU LI ${ }^{1}$, YIDI QI ${ }^{1}$, YUANZHU ZHANG ${ }^{1}$, \\ LONGTU LI $^{1}$, LIRONG TENG ${ }^{1}$ and DI WANG ${ }^{1}$ \\ ${ }^{1}$ School of Life Sciences, Jilin University, Changchun, Jilin 130012; ${ }^{2}$ College of Life \\ Sciences, Liaoning University, Shenyang, Liaoning 110036, P.R. China
}

Received November 8, 2016; Accepted June 21, 2017

DOI: $10.3892 / \mathrm{mmr} .2017 .7261$

\begin{abstract}
Paecilomyces hepiali contains identical chemical constituents to Cordyceps sinensis, and it presents antidepressant-like activity via regulating noradrenergic and dopaminergic systems. Behavioral despair depression models serve important roles in scientific screening and evaluation of antidepressants. The present study aims to investigate the antidepressant-like activity of $P$. hepiali extract (PHC) in chronic unpredictable mild stress (CUMS)-induced rat model of depression. Following four weeks of treatment, similar to fluoxetine at $3 \mathrm{mg} / \mathrm{kg}$ (positive drug), PHC at doses from 0.08 to $2.0 \mathrm{~g} / \mathrm{kg}$ strongly increased sucrose preference and reduced the immobility time of depression-like rats in forced swimming test. The hypo-level of adrenocorticotropic hormone, noradrenaline and glucocorticoid receptor in serum and hypothalamus of depression-like rats was enhanced by PHC. PHC normalized CUMS-induced disorders of dihydroxyphenylacetic acid, dopamine, 5-hydroxytryptamine (5-HT) and 5-hydroxyindoleacetic acid in serum and/or hypothalamus of depression-like rats. Moreover, PHC enhanced the expression of tyrosine hydroxylase and reduced the levels of dopamine D2 receptor and 5-HT2A receptor in hypothalamus. These results suggested that the antidepressant-like effects of PHC in CUMS-induced depression are associated with not only the modulation of dopamine, but also the regulation of 5-HT.
\end{abstract}

\section{Introduction}

Depression, a debilitating mental disorder, is a leading cause of disability worldwide (1), and $\sim 350$ million people currently suffer from depression (2). Although monoamine

Correspondence to: Dr Di Wang, School of Life Sciences, Jilin University, 2699 Qianjin Street, Changchun, Jilin 130012, P.R. China E-mail: jluwangdi@gmail.com

Key words: Paecilomyces hepiali, chronic unpredictable mild stress, anti-depression, dopamine, 5-HT deficiency and stress have been proposed as two major causes of depression (3), the pathogenic mechanisms have not been clearly understood. According to monoamine hypothesis, metabolites of both dopamine (DA) in the hippocampus and/or serotonin (5-HT) in the prefrontal cortex contribute to depression attack (4). Furthermore, the abnormal changes of 5-HT2A receptor, dopamine D2 receptor (DRD2), and tyrosine hydroxylase (TH) are observed in major depression patients $(5,6)$. In clinical mediation, four kinds of antidepressant drugs, including selective serotonin reuptake inhibitors (SSRIs), tricyclic antidepressants, serotonin-noradrenaline reuptake inhibitors and monoamine oxidase inhibitors, are commonly applied (7); however, it was difficult to predict their adverse reactions with high relapse rates and the long onset of therapeutic action (8). Due to the limited application of existing antidepressant drugs, the search for alternative therapies is highly demanded.

Herbal medicine is a valuable reservoir for novel drugs regarding its potent efficacy with few side effects, and it is also an effective alteration in depression therapy (9). As a precious medicinal product in China and other Asian countries, Cordyceps sinensis features with a broad spectrum of health benefits including antioxidant and immunomodulatory properties (10). The supercritical $C$. sinensis extract displays an antidepressant-like activity, which seems to originate from the alterations of noradrenergic and dopaminergic systems rather than the serotonergic system (11). Cordycepin (3'-deoxyadenosine), a major bioactive component isolated from $C$. militaris, shows antidepressant-like effects in a mice model induced by chronic unpredictable mild stress (12). Paecilomyces hepiali, a parasitic fungus generally found in $C$. sinensis, contains identical chemical constituents and similar bioactivities to $C$. sinensis (13). The authors previously confirmed various pharmacological activities of polysaccharide-enriching $P$. hepiali extract via regulating the oxidative system $(14,15)$. However, its potential regulatory effect on depression-like rat models and molecular mechanism has not been reported yet.

Therefore, it was hypothesized that $P$. hepiali mycelium aqueous extract (PHC) may possess an antidepressant-like property. To test this hypothesis, the biological activities of 
PHC on chronic unpredictable mild stress (CUMS)-induced depression-like rat models were analyzed. A forced swimming test (FST) was applied to test the effect of PHC on depression behaviors of rats. The levels of DA, 5-HT and related factors were detected to investigate the possible mechanism.

\section{Materials and methods}

P. hepiali mycelium aqueous preparation. P. hepiali (Preservation no. CCTCC M 2014670) was obtained from the China Center for Type Culture Collection (Wuhan, China), and cultured in a 1001 full-automatic fermenter (BaoXing Bio-engineering Equipment Co., Ltd., Shanghai, China; www. bxbio.com/Product.aspx?bid=54\&sid=0) with a defined liquid medium containing: $30 \mathrm{~g} / \mathrm{l}$ sucrose, $10 \mathrm{~g} / \mathrm{l}$ peptone, $18 \mathrm{~g} / \mathrm{l}$ yeast extract powder, $3.0 \mathrm{~g} / 1 \mathrm{MgSO}_{4} \cdot 7 \mathrm{H}_{2} \mathrm{O}, 3.0 \mathrm{~g} / 1 \mathrm{KH}_{2} \mathrm{PO}_{4} \cdot 3 \mathrm{H}_{2} \mathrm{O}$, $10 \mathrm{~g} / \mathrm{l}\left(\mathrm{NH}_{4}\right)_{2} \mathrm{SO}_{4}, 0.011 \mathrm{~g} / \mathrm{ZnCl}{ }_{2}$ and $0.25 \mathrm{~g} / 1$ vitamin $\mathrm{B}_{1}$. The fermentation conditions were as follows: Loading volume was $70 \mathrm{l} / 100 \mathrm{l}$, initial $\mathrm{pH}$ was 6.5 , rotation speed was $300 \mathrm{rpm}$, ventilation volume was $200 \mathrm{l} / \mathrm{h}$, culture temperature was $26^{\circ} \mathrm{C}$, inoculum age was 3.5 days, and inoculum size was $5 \%$. All the chemical reagents used in the submerged fermentation were obtained from Sigma-Aldrich; Merck KGaA (Darmstadt, Germany).

$P$. hepiali mycelium was extracted at $80^{\circ} \mathrm{C}$ two times for $4 \mathrm{~h}$ in double-distilled water. After centrifugation at $4,515 \mathrm{x} \mathrm{g}$ for $10 \mathrm{~min}$, the supernatant was sequentially concentrated in an evaporator (Buchi Labortechnik AG, Flawil, Switzerland) under reduced pressure and freeze-dried condition to produce solid aqueous extract. PHC contains $9.8 \%$ polysaccharides, $15.5 \%$ total proteins, $5.9 \%$ organic acid and $0.4 \%$ adenosine.

Open field test. The animal experimental protocol was approved by the Animal Ethics Committee of Jilin University (Changchun, China). Sprague Dawley male rats [six weeks; 180 to $220 \mathrm{~g}$; purchased from Norman Bethune University of Medical Science, Jilin University (Changchun, China; no. SCXK (JI)-2014-0013)] were maintained on a $12 \mathrm{~h}$ light/dark cycle (lights on from 7:00 to $19: 00$ ) at $23 \pm 1^{\circ} \mathrm{C}$ with water and food available ad libitum.

The open field test was conducted according to the method described previously (16). The apparatus was a gray wooden square box $(30 \mathrm{~cm}$ length $\times 30 \mathrm{~cm}$ width $\times 30 \mathrm{~cm}$ height) lined with black rubber. Sprague Dawley male rats were divided into four groups ( $\mathrm{n}=16 \mathrm{each}$ ) randomly, and orally treated with $2.0 \mathrm{ml} / \mathrm{kg}$ of sterile saline and $0.08,0.4$ and $2.0 \mathrm{~g} / \mathrm{kg}$ of PHC. A total of $10 \mathrm{~min}$ later, rats were individually placed in the center area of the box for $10 \mathrm{~min}$ free exploration. The total moving distance was recorded by a digital video camera positioned above the arena.

Depression-like rat model establishment and drug treatment procedure. The chronic stress procedure was described previously (17). Briefly, rats were exposed to different stressors daily including forced swimming for $5 \mathrm{~min}$ at $4^{\circ} \mathrm{C}, 12 \mathrm{~h}$ food deprivation and $12 \mathrm{~h}$ water deprivation, overnight illumination, $24 \mathrm{~h}$ damp bedding, 30 min noise, $8 \mathrm{~h}$ cage tilt $\left(40^{\circ} \mathrm{C}\right)$ and $1 \mathrm{~min}$ tail pinch. To prevent habituation, all stressors were randomly scheduled over one week and repeated throughout the 8 week experiments. All stressors were applied individually and continuously. The non-treated control rats were housed in a separate room without contact with the stressed groups. All rats were weighed every week, and drug treatment dosages were calculated depending on their bodyweights.

Depression-like rats were divided randomly into five groups of 16, and given oral treatments of $2.0 \mathrm{ml} / \mathrm{kg}$ of sterile saline solution (model group), $3.0 \mathrm{mg} / \mathrm{kg}$ of fluoxetine hydrochloride (Flu; purchased from Zhongxi Pharmaceutical Co., Ltd, Shanghai, China; positive control group), and 0.08, 0.4 and $2.0 \mathrm{~g} / \mathrm{kg}$ of PHC. Another 16 rats were given $2.0 \mathrm{ml} / \mathrm{kg}$ sterile saline solution and served as the normal control group. The drug treatment started following 4 weeks CUMS exposure and lasted for the next consecutive four weeks. Drug treatment was $1 \mathrm{~h}$ before the daily CUMS procedures.

Sucrose preference test. Following four weeks' treatment, rats were housed alone and trained to adapt to drinking sucrose water. Two bottles of $1 \%$ sucrose water were located randomly in every cage at the first two days, and at the third day, the water was replaced with tap water. After training, rats were deprived of food and water for $20 \mathrm{~h}$. A bottle of $1 \%$ sucrose water and a bottle of tap water were given to rats at random location in the cage. Then the consumption amount of $1 \%$ sucrose water and total liquid was measured in the next $2 \mathrm{~h}$. The sucrose preference index was calculated according to the following equation: Sucrose preference $=$ sucrose intake $(\mathrm{g}) /[$ sucrose intake $(\mathrm{g})+$ tap water intake $(\mathrm{g})]$ x $100 \%$ (18).

Forced swimming test (FST). At $30 \mathrm{~min}$ following the last administration, rats were placed in an open cylindrical container $(30 \times 32 \mathrm{~cm})$ with $29 \mathrm{~cm}$ depth and $24 \pm 1^{\circ} \mathrm{C}$ temperature water. A decrease in the immobility duration is a measurement of antidepressant-like activity. Immobility duration was defined as the time that the rat spent floating in the water without struggling and making only small movements necessary to keep its head above the water. The total immobility duration of each rat was recorded in the last $5 \mathrm{~min}$ in a 6 min test.

Blood and hypothalamus collection. Following the sucrose preference test, blood was obtained from the caudal vein after an overnight fast, and centrifuged at $972 \mathrm{x}$ g for $10 \mathrm{~min}$ at room temperature. The samples were stored at $-80^{\circ} \mathrm{C}$ for assay.

Hyperactivity of corticotropin-releasing factor (CRF) neurons in hypothalamus is a prominent feature in depression, and is considered to be the 'final common pathway' for a major part of the depressive symptomatology (19). The hypothalamus is responsible for certain metabolic processes and other activities of the autonomic nervous system. In neuroanatomy, hypothalamus forms the ventral part of the diencephalon, which is located below the thalamus. At the end of the experiments, rats were decapitated and the hypothalamus was quickly removed from the brains, weighed and frozen in $-80^{\circ} \mathrm{C}$ until the following experiment.

Neurotransmitters in serum and hypothalamus detection. An equal volume of $10 \%$ perchloric acid was added into plasma samples for deproteinization. Following centrifugation at $9,724 \mathrm{x}$ g for $20 \mathrm{~min}$ at $4^{\circ} \mathrm{C}$, supernatants were collected for high 
performance liquid chromatography (HPLC) analysis. The methodology was similar as the previous study (20). The chromatographic system consists of a Waters 510 solvent delivery pump (Waters Corporation, Milford, MA, USA), a Rheodyne 7725 (Sigma-Aldrich; Merck KGaA) injector, and a Waters 460 electrochemical detector with glassy carbon electrode (Waters Corporation). The columns used were a C18 column $(5 \mathrm{~mm}$, $250 \times 4.6 \mathrm{~mm})$ and a C18 guard column (5 mm, 30x4.6 mm) from Phenomenex (Torrance, CA, USA). The mobile phase ( $1 \mathrm{ml} / \mathrm{min}$ flow rate) was $0.1 \mathrm{M}$ citric acid, $0.05 \mathrm{mM} \mathrm{Na}{ }_{2}$ EDTA, $225 \mathrm{mg} / \mathrm{l} \mathrm{HSA}$ and $8.5 \%$ acetonitrile (apparent $\mathrm{pH}$ 2.71). The concentration of dihydroxyphenylacetic acid (DOPAC), and noradrenalin (NE), 5-hydroxyindoleacetic acid (5-HIAA) and 5-hydroxytryptamine (5-HT) in serum were analyzed by the HPLC system. A chromatography Station for Windows ( $\mathrm{p} / \mathrm{n}$ A24, DataApex, Prague, Czech Republic) was used for the quantitative analysis of peaks in the chromatograms.

The concentration of glucocorticoid receptor (GR; cat. no. YY41836) and adrenocorticotropic hormone (ACTH; cat. no. YY02106B) in serum were measured using commercially available ELISA kits (R\&D systems, USA) following the manufacturer's instructions.

One part of hypothalamus was dissected, weighed and lysed with double distilled water. The concentration of DA (cat. no. YY41896), 5-HT (cat. no. YY41983), 5-HIAA (cat. no. YY41497), GR, ACTH, DOPAC (cat. no. YY18432) and NE (cat. no. YY 42097) was measured using commercially available ELISA kits (R\&D Systems, Inc., Minneapolis, MN, USA) following the manufacturer's instructions.

Western blotting. One part of hypothalamus was homogenized in radioimmunoprecipitation assay buffer (Sigma-Aldrich; Merck $\mathrm{KGaA}$ ) containing $1 \%$ protease inhibitor cocktail (Sigma-Aldrich; Merck KGaA) and 2\% phenylmethanesulfonyl fluoride (Sigma-Aldrich; Merck KGaA). Protein concentrations were determined by Bradford method, and $40 \mu \mathrm{g}$ proteins were separated using a 10\% SDS-PAGE gel and transferred electrophoretically onto nitrocellulose membranes $(0.45 \mu \mathrm{m}$; Bio Basic, Inc., Markham, ON, Canada). The transferred membranes were then blotted at $4^{\circ} \mathrm{C}$ overnight with the primary antibodies against the dopamine receptor D2 (DRD2; cat. no. sc-5303), tyrosine hydroxylase (TH; cat. no. sc-73152), 5-hydroxytryptamine receptor 2A (5-HT2A receptor; cat. no. sc-166775) and GAPDH (cat. no. sc-47724) (Santa Cruz Biotechnology, Inc., Dallas, TX, USA) at a dilution of $1: 1,000$, and it was followed by incubation with horseradish peroxidase-conjugated secondary antibodies $(1: 2,000$, cat. no. sc-358914) at room temperature for $2 \mathrm{~h}$. Chemiluminescence was detected using an enhanced chemiluminescence detection kit (cat. no. RPN2134, GE Healthcare Life Sciences, Little Chalfont, UK). The intensity of the bands was quantified by scanning densitometry using ImageJ software Image (v2.1.4.7, National Institutes of Health, Bethesda, MD, USA).

Statistical analysis. All values were expressed as mean \pm standard error of the mean. A one-way analysis of variance was used to detect statistical significance followed by post-hoc multiple comparisons (Dunn's test) using SPSS 16.0 software (SPSS Inc., Chicago, IL, USA). $\mathrm{P}<0.05$ was considered to indicate a statistically significant difference.

\section{Results}

Antidepressant-like activity of PHC. PHC reported no significant effects on rat moving distance in open field ( $\mathrm{P}>0.05$; Table I). At the second week, CUMS reduced nearly $22.7 \%$ body weight of rats compared with non-treated control group $(\mathrm{P}<0.001$; Table II). Four weeks $\mathrm{PHC}$ and Flu treatment made the CUMS rats regained body weight $(\mathrm{P}<0.05$; Table II). Sucrose preference tests were used to operationally define anhedonia. Compared with CUMS rats, 0.4 and $2.0 \mathrm{~g} / \mathrm{kg}$ of PHC resulted in nearly 53.0 and $73.9 \%$ increment on sucrose preference $(\mathrm{P}<0.05$; Fig. 1A). Similar to Flu, PHC strongly reduced immobility time in FST in CUMS rats $(87.5 \mathrm{sec}$ vs. $141.8 \mathrm{sec}$ in CUMS rats; $\mathrm{P}<0.01$; Fig. 1B).

PHC regulating neurotransmitters and hormones in serum. A significant reduction in serum levels of 5-HT, ACTH and NE were observed in CUMS rats $(\mathrm{P}<0.05$; Table III). Like Flu, PHC at $2.0 \mathrm{~g} / \mathrm{kg}$ strikingly increased the concentration of 5-HT, GR and NE up to 30.4, 15.5 and 28.1\% in CUMS rats $(\mathrm{P}<0.05$; Table III). However, $\mathrm{PHC}$ and Flu fail to influence the levels of 5-HIAA and DOPAC (P>0.05; Table III).

PHC regulating $G R, A C T H$ and NE levels in hypothalamus. A significant reduction in the levels of GR, ACTH and NE in hypothalamus was observed in CUMS rats $(\mathrm{P}<0.05$; Fig. 2). Unlike Flu, PHC strikingly increased the hypothalamic concentration of GR, ACTH and NE up to $29.9 \%(\mathrm{P}<0.001)$, $23.1 \%(\mathrm{P}<0.05)$ and $22.1 \%(\mathrm{P}<0.001)$, respectively (Fig. 2).

Dopaminergic system involved in PHC-mediated antidepressant-like effects. CUMS strongly suppressed DA rather than DOPAC concentration in hypothalamus of depression-like rats $(\mathrm{P}<0.05$; Fig. $3 \mathrm{~A})$. $\mathrm{PHC}$ at $2.0 \mathrm{~g} / \mathrm{kg}$ enhanced $\sim 8.2 \% \mathrm{DA}$ concentration $(\mathrm{P}<0.05$; Fig. $3 \mathrm{~A})$ and $10.4 \%$ DOPAC concentration $(\mathrm{P}<0.01$; Fig. $3 \mathrm{~B})$ in the hypothalamus compared with CUMS rats.

Similar to Flu, PHC significantly increased CUMS-suppressed TH expression (109.5 and $148.5 \%$ vs. 95.9\% in CUMS rats) ( $\mathrm{P}<0.05$; Fig. $3 \mathrm{C}$ and $\mathrm{D})$. A $25.7 \%$ reduction on DRD2 expression in hypothalamus of PHC-treated rats was observed compared with CUMS rats $(\mathrm{P}<0.01$; Fig. $3 \mathrm{C}$ and D).

Serotonin related pathway involved in $\mathrm{PHC}$-mediated antidepressant-like effects. Compared with the non-treated control group, 10.0 and $7.8 \%$ reduction on 5-HT and 5-HIAA in the hypothalamus of CUMS rats were noted $(\mathrm{P}<0.05$; Fig. $4 \mathrm{~A}$ and B). Flu enhanced nearly $7.2 \%$ hypothalamic 5-HT level; similarly, PHC ranging from 0.08 to $2.0 \mathrm{~g} / \mathrm{kg}$ increased 17.3 to $32.6 \% 5$-HT level compared with CUMS rats $(\mathrm{P}<0.001$; Fig. 4A). PHC rather than Flu enhanced hypothalamic 5-HIAA concentration $(\mathrm{P}<0.05$; Fig. 4B). Both Flu and $\mathrm{PHC}$ reduced the CUMS-enhanced 5-HT2A receptor expression in the hypothalamus of depression-like rats $(\mathrm{P}<0.05$; Fig. $4 \mathrm{C}$ and $\mathrm{D})$.

\section{Discussion}

Behavioral despair depression models play important roles in scientific screening and evaluation of antidepressants (21). 
Table I. Effects of PHC on the distance traveled of rats in the open field test were analyzed.

\begin{tabular}{|c|c|c|c|c|}
\hline Variable & $\mathrm{NC}$ & PHC (L) & PHC (M) & $\mathrm{PHC}(\mathrm{H})$ \\
\hline Moving distance $(\mathrm{m})$ & $25.5 \pm 3.2$ & $26.1 \pm 2.12$ & $24.8 \pm 3.09$ & $23.9 \pm 4.0$ \\
\hline
\end{tabular}

Table II. Regulatory effects of Flu and PHC on the bodyweight changes in CUMS rats.

\begin{tabular}{lllllll}
\hline Week & \multicolumn{1}{c}{ NC } & \multicolumn{1}{c}{ CUMS } & \multicolumn{1}{c}{ Flu } & PHC $(\mathrm{L})$ & PHC $(\mathrm{M})$ & PHC $(\mathrm{H})$ \\
\hline Week 1 & $240.8 \pm 3.1$ & $235.5 \pm 4.2$ & $240.4 \pm 3.6$ & $229.3 \pm 3.4$ & $232.9 \pm 8.0$ & $229.3 \pm 4.3$ \\
Week 2 & $329.7 \pm 16.8$ & $255.0 \pm 5.9^{\mathrm{a}}$ & $265.3 \pm 11.4$ & $253.7 \pm 7.9$ & $263.3 \pm 11.5$ & $259.5 \pm 10.2$ \\
Week 3 & $365.6 \pm 9.8$ & $274.6 \pm 6.3^{\mathrm{a}}$ & $272.3 \pm 13.5$ & $269.9 \pm 6.5$ & $265.6 \pm 11.3$ & $275.5 \pm 10.7$ \\
Week 4 & $385.5 \pm 9.6$ & $301.3 \pm 5.9^{\mathrm{a}}$ & $311.4 \pm 7.4$ & $312.3 \pm 6.9$ & $311.8 \pm 8.0$ & $318.8 \pm 7.7$ \\
Week 5 & $391.3 \pm 5.8$ & $329.2 \pm 14.4^{\mathrm{a}}$ & $357.1 \pm 15.1$ & $359.2 \pm 7.3$ & $357.5 \pm 4.7$ & $357.3 \pm 7.5$ \\
Week 6 & $399.0 \pm 10.5$ & $330.8 \pm 15.8^{\mathrm{b}}$ & $381.7 \pm 18.2^{\mathrm{c}}$ & $378.8 \pm 11.8^{\mathrm{c}}$ & $373.4 \pm 10.6^{\mathrm{c}}$ & $373.9 \pm 6.2^{\mathrm{c}}$ \\
Week 7 & $404.1 \pm 6.1$ & $331.2 \pm 12.6^{\mathrm{b}}$ & $390.4 \pm 12.9^{\mathrm{d}}$ & $390.6 \pm 16.1^{\mathrm{c}}$ & $382.2 \pm 15.3^{\mathrm{c}}$ & $385.4 \pm 7.9^{\mathrm{d}}$ \\
Week 8 & $406.0 \pm 4.0$ & $337.1 \pm 14.1^{\mathrm{b}}$ & $400.1 \pm 11.8^{\mathrm{d}}$ & $395.1 \pm 14.5^{\mathrm{c}}$ & $389.4 \pm 12.3^{\mathrm{c}}$ & $401.9 \pm 8.3^{\mathrm{d}}$ \\
\hline
\end{tabular}

The changes on bodyweight in all experimental groups were monitored every week during CUMS process and drug administration period. Data are expressed as mean \pm standard error $(\mathrm{n}=16)$ and analyzed by a one-way ANOVA. ${ }^{\mathrm{a}} \mathrm{P}<0.001,{ }^{\mathrm{b}} \mathrm{P}<0.01 \mathrm{vs} . \mathrm{NC}$ group; ${ }^{\mathrm{C}} \mathrm{P}<0.05,{ }^{\mathrm{d}} \mathrm{P}<0.01$ vs. CUMS group. NC, non-treated control group; CUMS, chronic unpredictable mild stress induced depression-like rat; Flu, fluoxetine hydrochloride $(3.0 \mathrm{mg} / \mathrm{kg})$ group; PHC (L), low dose P. hepiali extract $(0.08 \mathrm{~g} / \mathrm{kg})$ group; PHC (M), medium dose P. hepiali extract $(0.4 \mathrm{~g} / \mathrm{kg})$ group; PHC $(\mathrm{H})$, high dose P. hepiali extract $(2.0 \mathrm{~g} / \mathrm{kg})$ group.
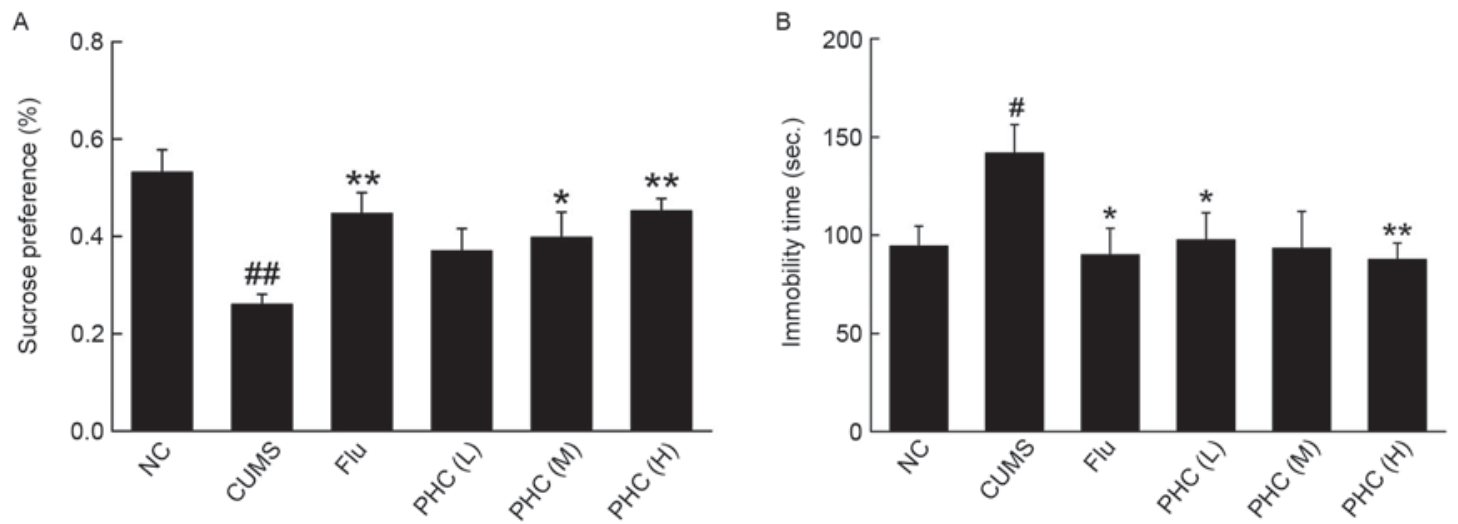

Figure 1. Following a 4 week PHC $(0.08,0.4$ and $2.0 \mathrm{~g} / \mathrm{kg})$ or fluoxetine $(3.0 \mathrm{mg} / \mathrm{kg})$ treatment, (A) sucrose preference and (B) the immobility time in forced swimming test were detected. Data are expressed as mean \pm standard error of the mean $(\mathrm{n}=16) .{ }^{*} \mathrm{P}<0.05$ and ${ }^{\# \#} \mathrm{P}<0.01$ vs. NC; ${ }^{*} \mathrm{P}<0.05$ and ${ }^{* *} \mathrm{P}<0.01$ vs. CUMS rats. PHC (L), low dose P. hepiali extract $(0.08 \mathrm{~g} / \mathrm{kg})$ group; PHC (M), medium dose P. hepiali extract $(0.4 \mathrm{~g} / \mathrm{kg})$ group; PHC $(\mathrm{H})$, high dose $P$. hepiali extract $(2.0 \mathrm{~g} / \mathrm{kg})$ group; NC, non-treated control group; CUMS, chronic unpredictable mild stress induced depression-like rat; Flu, fluoxetine hydrochloride $(3.0 \mathrm{mg} / \mathrm{kg})$ group.

CUMS involves making rodents suffer from a series of repeated physical stressors for a prolonged period of time, which results in the development of anhedonic features, and thus makes it more closely resemble the chronic and multidimensional nature of clinical major depressive disorder (22). The current study investigates the antidepressant-like effects of PHC and its underlying mechanisms on CUMS-induced depression-like rats.
P. hepiali is a traditional Chinese medicine, and its crude nature suggests multi-effective components, which might target multi-molecules. The "systemic targeting" will eliminate the depression in a much natural way, so that fewer adverse side effects are expected. It may also explain its non-dose dependent manner observed in our present data. As reported, an amount of a natural product displaying pharmacological activities via 
Table III. Effects of Flu and PHC on neurotransmitters and hormones in serum.

\begin{tabular}{lcccccc}
\hline & $5-\mathrm{HT}(\mathrm{ng} / \mathrm{ml})$ & 5-HIAA $(\mathrm{ng} / \mathrm{ml})$ & DOPAC $(\mathrm{ng} / \mathrm{ml})$ & GR $(\mathrm{ng} / \mathrm{ml})$ & $\mathrm{NE}(\mathrm{ng} / \mathrm{ml})$ & $\mathrm{ACTH}(\mathrm{pg} / \mathrm{ml})$ \\
\hline NC & $10.0 \pm 0.7$ & $3.4 \pm 0.1$ & $23.9 \pm 1.6$ & $1.22 \pm 0.07$ & $11.8 \pm 0.6$ & $11.9 \pm 0.5$ \\
CUMS & $7.9 \pm 0.3^{\mathrm{a}}$ & $3.6 \pm 0.2$ & $21.9 \pm 1.6$ & $1.16 \pm 0.08$ & $8.9 \pm 0.2^{\mathrm{a}}$ & $9.4 \pm 0.7^{\mathrm{a}}$ \\
Flu & $9.5 \pm 0.6^{\mathrm{b}}$ & $3.3 \pm 0.1$ & $21.6 \pm 1.0$ & $1.18 \pm 0.05$ & $12.4 \pm 0.2^{\mathrm{c}}$ & $10.7 \pm 0.8^{\mathrm{b}}$ \\
PHC (L) & $9.3 \pm 0.4^{\mathrm{b}}$ & $3.5 \pm 0.2$ & $21.4 \pm 0.9$ & $1.09 \pm 0.05$ & $10.4 \pm 0.2^{\mathrm{b}}$ & $11.5 \pm 0.7^{\mathrm{b}}$ \\
PHC (M) & $10.4 \pm 0.5^{\mathrm{b}}$ & $3.4 \pm 0.3$ & $21.4 \pm 1.5$ & $1.18 \pm 0.05$ & $9.9 \pm 0.3^{\mathrm{b}}$ & $11.2 \pm 0.9$ \\
PHC (H) & $10.3 \pm 0.4^{\mathrm{b}}$ & $3.5 \pm 0.2$ & $22.3 \pm 1.2$ & $1.34 \pm 0.09^{\mathrm{b}}$ & $11.4 \pm 0.4^{\mathrm{b}}$ & $10.7 \pm 0.3$ \\
\hline
\end{tabular}

The changes on neurotransmitters and hormones in serum were analyzed via high performance liquid chromatography and ELISA. Data are expressed as mean \pm standard error of mean $(\mathrm{n}=16)$ and analyzed by a one-way analysis of variance. ${ }^{\mathrm{a}} \mathrm{P}<0.05$ vs. $\mathrm{NC}$ group, ${ }^{\text {b } \mathrm{P}<0.05 \text { and }}$ ${ }^{\mathrm{c}} \mathrm{P}<0.01$ vs. CUMS group. 5-HT, 5-hydroxytryptamine; 5-HIAA, 5-hydroxyindoleacetic acid; DOPAC, dihydroxyphenyl acetic acid; GR, glucocorticoid receptor; NE, noradrenalin; ACTH, adrenocorticotrophic hormone; NC, non-treated control group; CUMS, chronic unpredictable mild stress induced depression-like rat; Flu, fluoxetine hydrochloride $(3.0 \mathrm{mg} / \mathrm{kg})$ group; PHC (L), low dose P. hepiali extract (0.08 g/kg) group; PHC (M), medium dose P. hepiali extract $(0.4 \mathrm{~g} / \mathrm{kg})$ group; PHC $(\mathrm{H})$, high dose $P$. hepiali extract $(2.0 \mathrm{~g} / \mathrm{kg}) \mathrm{group}$.
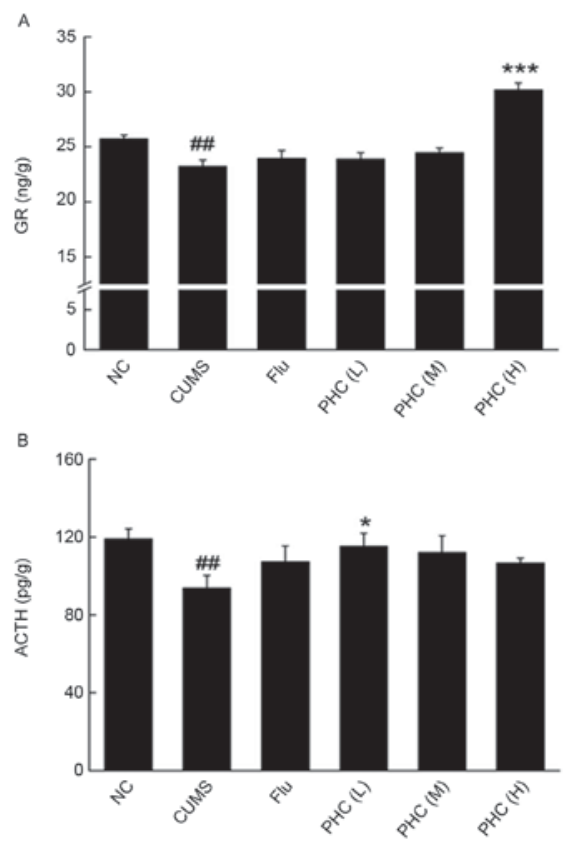

$\mathrm{c}$

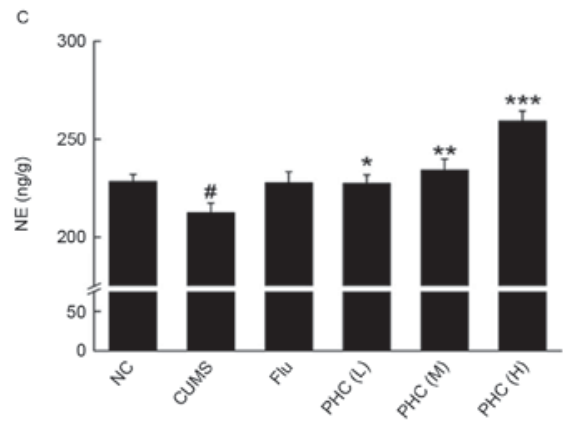

Figure 2. CUMS-induced depression-like rats were treated with PHC $(0.08$, 0.4 and $2.0 \mathrm{~g} / \mathrm{kg}$ ) and fluoxetine $(3.0 \mathrm{mg} / \mathrm{kg})$ orally for 4 weeks. The levels of (A) GR, (B) ACTH and (C) NE in hypothalamus were analyzed via ELISA method. Data are expressed as mean \pm standard error of the mean $(n=16)$. ${ }^{\#} \mathrm{P}<0.05$ and $^{\# \#} \mathrm{P}<0.01$ vs. $\mathrm{NC} ;{ }^{*} \mathrm{P}<0.05,{ }^{* *} \mathrm{P}<0.01$ and $^{* * * *} \mathrm{P}<0.001$ vs. CUMS rats. PHC (L), low dose P. hepiali extract $(0.08 \mathrm{~g} / \mathrm{kg})$ group; PHC (M), medium dose $P$. hepiali extract $(0.4 \mathrm{~g} / \mathrm{kg})$ group; PHC $(\mathrm{H})$, high dose $P$. hepiali extract $(2.0 \mathrm{~g} / \mathrm{kg})$ group; CUMS, chronic unpredictable mild stress induced depression-like rat; GR, glucocorticoid receptor; ACTH, adrenocorticotropic hormone; NE noradrenalin; NC, non-treated control group; Flu, fluoxetine hydrochloride $(3.0 \mathrm{mg} / \mathrm{kg})$ group. non-dose dependent manner is considered common among natural drugs $(23,24)$.

Reduced immobility time in FST following 4 week PHC treatment indicated its antidepressant-like effects. Distress evoked changes in neurotransmitters and stress hormones are associated with fear or certain types of anxiety-related behaviors (25). All these abnormal changes were observed in CUMS rats, which were normalized by PHC. Monoamine hypothesis points out that patients with major depression show a deficit in brain DA and/or DA metabolites (26). Antidepressants display therapeutic effects via increasing DA receptors expressions and DA levels (27). As an important enzyme, TH limits DA synthesis (28), which is enhanced following PHC treatment in hypothalamus of CUMS rats. On the other hand, DRD2 has been confirmed as a target for the pharmacological treatment of depressive rumination (29), which is involved in mediating the stress response and neuronal mechanism of depression (30). The reduced DRD2 expression was successfully observed in PHC-treated CUMS rats. Based on the present data, the dopaminergic system contributes to PHC-mediated anti-depressive like effects. On the other hand, DA is reported as the premise compounds of NE and it can be converted into DOPAC (31). A study on the noradrenergic system demonstrated that decreased levels of noradrenalin transporter are detected in patients with major depression (32). Due to the action on 5-HT and NE re-uptake, milnacipran effectively relieves depressive behaviors in patients (33). However, the detail roles of NE during the anti-depressive like effects of PHC need further investigation.

Clinical data reveal that platelet 5-HT and 5-HT1A receptor levels could serve as peripheral markers for the diagnosis of depression (34). PHC restored CUMS-reduced 5-HT and 5-HIAA concentration, and suppressed 5-HT2A receptor expression in the hypothalamus of depression-like rats. Atypical antipsychotic drugs augment the clinical response to SSRIs in treatment-resistant patients. One common feature of these atypical antipsychotic drugs is that they are able to occupy 5-HT2 receptors in the brain and more specifically to block 5-HT2A-mediated responses (35). Blockade of the 

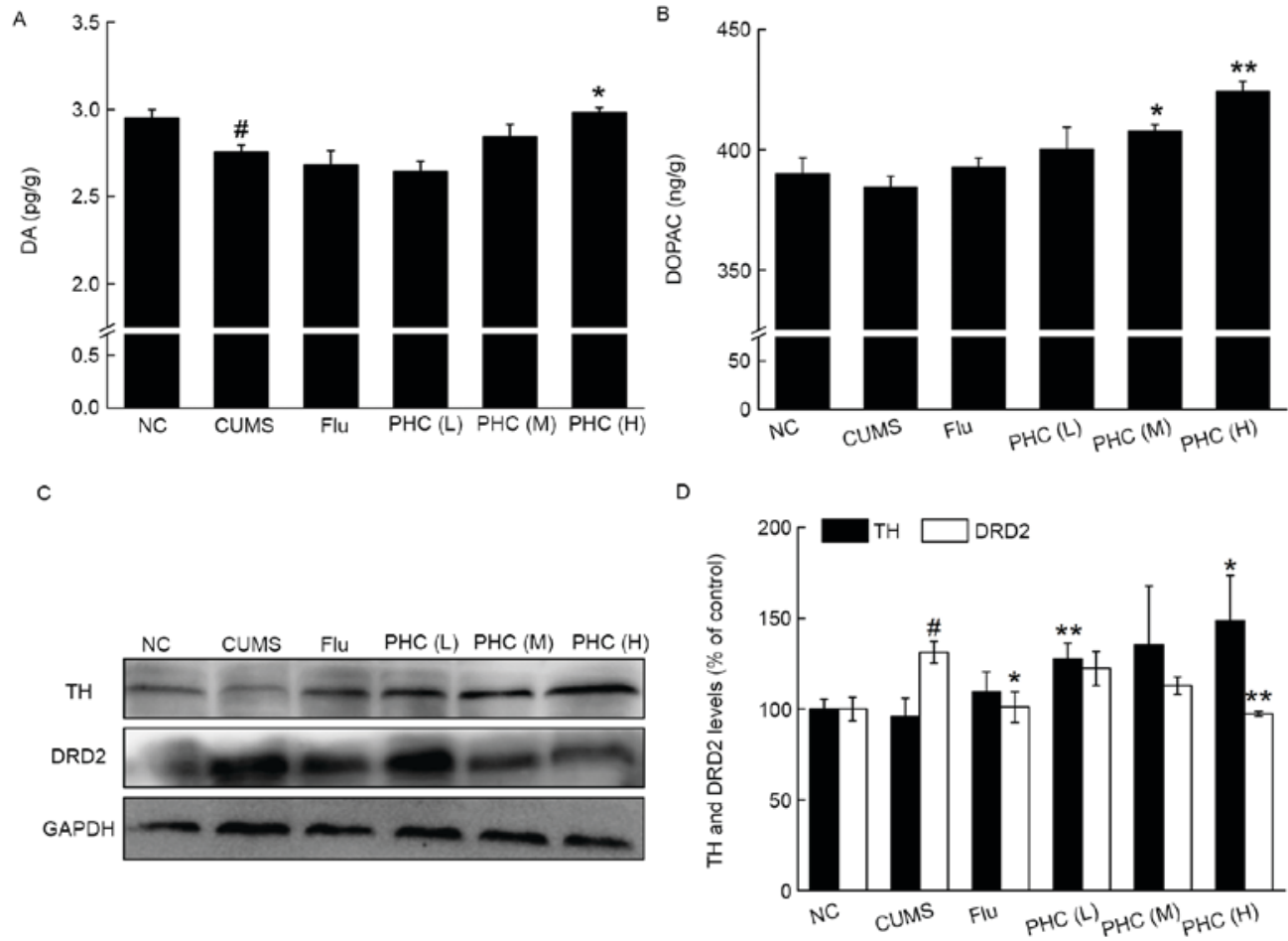

Figure 3. PHC-mediated antidepressant-like activity in CUMS rats was related to the dopaminergic system. CUMS rats were treated with PHC $(0.08,0.4$ and $2.0 \mathrm{~g} / \mathrm{kg}$ ) and fluoxetine $(3.0 \mathrm{mg} / \mathrm{kg}$ ) orally for four weeks. The levels of (A) DA and (B) DOPAC in rat hypothalamus were measured. (C) The hypothalamic expressions of TH and DRD2 were analyzed via western blotting. (D) Quantification data were normalized by GAPDH respectively and expressed as a percent of that from corresponding non-treated control rats. Data are expressed as mean \pm standard error of the mean $(\mathrm{n}=16) .{ }^{~} \mathrm{P}<0.05 \mathrm{vs}$. $\mathrm{NC} ;{ }^{*} \mathrm{P}<0.05,{ }^{* *} \mathrm{P}<0.01 \mathrm{vs}$. CUMS rats. CUMS, chronic unpredictable mild stress induced depression-like rat; PHC (L), low dose P. hepiali extract $(0.08 \mathrm{~g} / \mathrm{kg}$ ) group; PHC (M), medium dose $P$. hepiali extract $(0.4 \mathrm{~g} / \mathrm{kg})$ group; PHC $(\mathrm{H})$, high dose $P$. hepiali extract $(2.0 \mathrm{~g} / \mathrm{kg})$ group; DA, dopamine; DOPAC, dihydroxyphenyl acetic acid; TH, tyrosine hydroxylase; DRD2, dopamine D2 receptor; NC, non-treated control group; Flu, fluoxetine hydrochloride $(3.0 \mathrm{mg} / \mathrm{kg}) \mathrm{group}$.
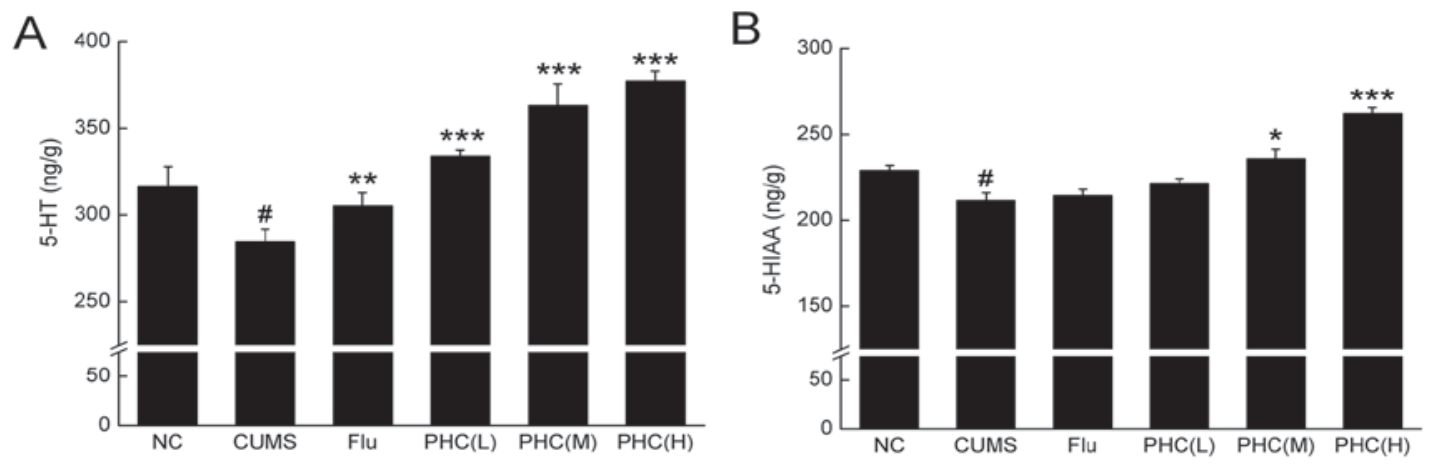

C

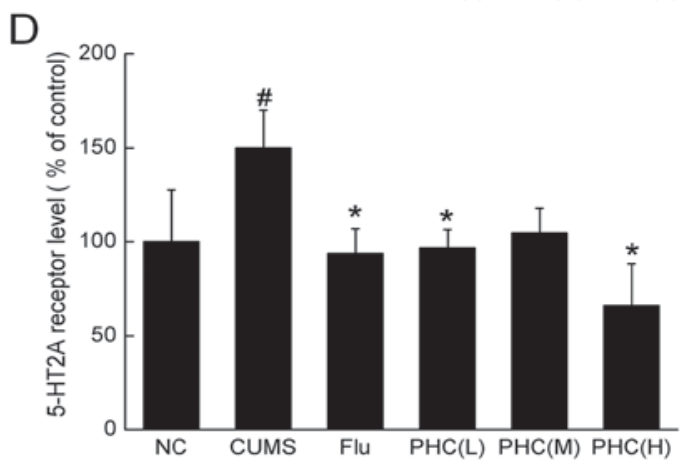

Figure 4. The serotonergic system was involved in the PHC-mediated antidepressant-like effect. Following 4 weeks of treatment, the levels of (A) 5-HT and (B) 5-HIAA in the rat hypothalamus were measured. (C) The alteration of 5-HT2A receptor in the hypothalamus was determined by western blotting. (D) Quantification of data was normalized by GAPDH and expressed as a percentage of that from corresponding non-treated control rats. Data are expressed as mean \pm standard error of the mean $(\mathrm{n}=16) .{ }^{~} \mathrm{P}<0.05 \mathrm{vs}$. NC; ${ }^{*} \mathrm{P}<0.05,{ }^{* *} \mathrm{P}<0.01 .{ }^{* * *} \mathrm{P}<0.001$ vs. CUMS rats. PHC $(\mathrm{L})$, low dose $P$. hepiali extract $(0.08 \mathrm{~g} / \mathrm{kg})$ group; PHC (M), medium dose $P$. hepiali extract $(0.4 \mathrm{~g} / \mathrm{kg})$ group; PHC $(\mathrm{H})$, high dose $P$. hepiali extract $(2.0 \mathrm{~g} / \mathrm{kg})$ group; 5-HT, 5-hydroxytryptamine; 5-HIAA, 5-hydroxyindoleacetic acid; 5-HT2A receptor, 5-hydroxytryptamine receptor 2A; NC, non-treated control group; CUMS, chronic unpredictable mild stress induced depression-like rat; Flu, fluoxetine hydrochloride $(3.0 \mathrm{mg} / \mathrm{kg})$ group. 
5-HT2A receptor enhances the 5-HT1A receptor-mediated neurotransmission in cortical and limbic areas, which links to the antidepressant efficacy (35). The modulation of PHC on serotonergic system may be involved in its antidepressant-like activity.

There is still a limitation in the current study. 5-HT2A receptor antagonists increase the firing rate of midbrain dopaminergic neurons in a state-dependent manner, and induce the activity of nigrostriatal DA-containing neurons (36). As reported, 5-HT2A receptors in the prefrontal cortex regulate mesocortical DA release (37). However, based on the data, it is hard to confirm the relationship between the dopaminergic and serotonergic systems on PHC-mediated antidepressant-like effects.

Taken together, the present study demonstrated that PHC possesses antidepressant-like activity, which may be related to its modulation of the dopaminergic system and the serotonergic system. The experimental evidence was provided in supporting the clinical use of PHC as an effective agent against major depression.

\section{Acknowledgements}

The present study was supported by the Science and Technology Key Project in Jilin Province of China (grant nos. 20140301003YY, 20150203002NY and 20160520036JH), and the "Twelfth Five-Year" Science and Technology Planning Project of Jilin Province in China (grant no. 2014B033).

\section{References}

1. Williams NR and Schatzberg AF: NMDA antagonist treatment of depression. Curr Opin Neurobiol 36: 112-117, 2016.

2. Sim K, Lau WK, Sim J, Sum MY and Baldessarini RJ: Prevention of relapse and recurrence in adults with major depressive disorder: Systematic review and meta-analyses of controlled trials. Int J Neuropsychopharmacol 19: pii: pyv076, 2015.

3. Andrus BM, Blizinsky K, Vedell PT, Dennis K, Shukla PK, Schaffer DJ, Radulovic J, Churchill GA and Redei EE: Gene expression patterns in the hippocampus and amygdala of endogenous depression and chronic stress models. Mol Psychiatry 17: 49-61, 2012.

4. Wilson CB, Ebenezer PJ, McLaughlin LD and Francis J: Predator exposure/psychosocial stress animal model of post-traumatic stress disorder modulates neurotransmitters in the rat hippocampus and prefrontal cortex. PLoS One 9: e89104, 2014.

5. Redmond AM and Leonard BE: An evaluation of the role of the noradrenergic system in the neurobiology of depression: A review. Hum Psychopharmacol Clin Exp 12: 407-430, 1997.

6. Marek GJ, Carpenter LL, McDougle CJ and Price LH: Synergistic action of 5-HT2A antagonists and selective serotonin reuptake inhibitors in neuropsychiatric disorders. Neuropsychopharmacology 28: 402-412, 2003.

7. Anderson HD, Pace WD, Libby AM, West DR and Valuck RJ: Rates of 5 common antidepressant side effects among new adult and adolescent cases of depression: A retrospective US claims study. Clin Ther 34: 113-123, 2012.

8. Connolly KR and Thase ME: If at first you don't succeed: A review of the evidence for antidepressant augmentation, combination and switching strategies. Drugs 71: 43-64, 2011.

9. Russo E, Scicchitano F, Whalley BJ, Mazzitello C, Ciriaco M, Esposito S, Patanè M, Upton R, Pugliese M, Chimirri S, et al: Hypericum perforatum: Pharmacokinetic, mechanism of action, tolerability and clinical drug-drug interactions. Phytother Res 28: 643-655, 2014

10. Li SP, Su ZR, Dong TT and Tsim KW: The fruiting body and its caterpillar host of Cordyceps sinensis show close resemblance in main constituents and anti-oxidation activity. Phytomedicine 9: 319-324, 2002
11. Nishizawa K, Torii K, Kawasaki A, Katada M, Ito M, Terashita K, Aiso S and Matsuoka M: Antidepressant-like effect of Cordyceps sinensis in the mouse tail suspension test. Biol Pharm Bull 30: 1758-1762, 2007.

12. Tianzhu Z, Shihai Y and Juan D: Antidepressant-like effects of cordycepin in a mice model of chronic unpredictable mild stress. Evid Based Complement Alternat Med 2014: 438506, 2014.

13. Yang JL, Xiao W, He HX, Zhu HX, Wang SF, Cheng KD and Zhu P: Molecular phylogenetic analysis of Paecilomyces hepiali and Cordyceps sinensis. Yao Xue Xue Bao 43: 421-426, 2008 (In Chinese)

14. Wang J, Li LZ, Liu YG, Teng LR, Lu JH, Xie J, Hu WJ, Liu Y, Liu Y, Wang D and Teng le S: Investigations on the antifatigue and antihypoxic effects of Paecilomyces hepiali extract. Mol Med Rep 13: 1861-1868, 2016.

15. Wang J, Teng L, Liu Y, Hu W, Chen W, Hu X, Wang Y and Wang D: Studies on the antidiabetic and antinephritic activities of Paecilomyces hepiali water extract in diet-streptozotocin-induced diabetic sprague dawley rats. J Diabetes Res 2016: 4368380, 2016.

16. Buijs S and Tuyttens FAM: Evaluating the effect of semi-group housing of rabbit does on their offspring's fearfulness: Can we use the open-field test? Applied Animal Behaviour Science 162: 58-66, 2015.

17. Liu XJ, Li ZY, Li ZF, Gao XX, Zhou YZ, Sun HF, Zhang LZ, Guo XQ, Du GH and Qin XM: Urinary metabonomic study using a CUMS rat model of depression. Magn Reson Chem 50: 187-192, 2012.

18. Gross $\mathrm{M}$ and Pinhasov A: Chronic mild stress in submissive mice: Marked polydipsia and social avoidance without hedonic deficit in the sucrose preference test. Behav Brain Res 298: 25-34, 2016.

19. Wang SS, Kamphuis W, Huitinga I, Zhou JN and Swaab DF: Gene expression analysis in the human hypothalamus in depression by laser microdissection and real-time PCR: The presence of multiple receptor imbalances. Mol Psychiatry 13: 786-799. 741,2008

20. Liu YL, Cheng AT, Chen HR and Hsu YP: Simultaneous HPLC of twelve monoamines and metabolites shows neuroblastoma cell line releases HVA and HIAA. Biomed Chromatogr 14: 544-548, 2000.

21. Yan Y, Wang YL, Su Z, Zhang Y, Guo SX, Liu AJ, Wang CH, Sun FJ and Yang J: Effect of oxytocin on the behavioral activity in the behavioral despair depression rat model. Neuropeptides 48 : 83-89, 2014.

22. Malki K, Mineur YS, Tosto MG, Campbell J, Karia P, Jumabhoy I, Sluyter F, Crusio WE and Schalkwyk LC: Pervasive and opposing effects of Unpredictable Chronic Mild Stress (UCMS) on hippocampal gene expression in BALB/cJ and C57BL/6 J mouse strains. BMC Genomics 16: 262, 2015.

23. Wei J,Wang S,Liu G,Pei D, Liu Y,Liu Y and Di D: Polysaccharides from Enteromorpha prolifera enhance the immunity of normal mice. Int J Biol Macromol 64: 1-5, 2014.

24. Ma L, Zhang S and Du M: Cordycepin from Cordyceps militaris prevents hyperglycemia in alloxan-induced diabetic mice. Nutr Res 35: 431-439, 2015.

25. Mariappan S, Bogdanowicz W, Marimuthu G and Rajan KE: Distress calls of the greater short-nosed fruit bat Cynopterus sphinx activate hypothalamic-pituitary-adrenal (HPA) axis in conspecifics. J Comp Physiol A Neuroethol Sens Neural Behav Physiol 199: 775-783, 2013.

26. Lambert G, Johansson M, Agren H and Friberg P: Reduced brain norepinephrine and dopamine release in treatment-refractory depressive illness: Evidence in support of the catecholamine hypothesis of mood disorders. Arch Gen Psychiatry 57: 787-793, 2000.

27. Ainsworth K, Smith SE, Zetterström TS, Pei Q, Franklin M and Sharp T: Effect of antidepressant drugs on dopamine D1 and D2 receptor expression and dopamine release in the nucleus accumbens of the rat. Psychopharmacology (Berl) 140: 470-477, 1998

28. Li Y, Sun Y, Yang J, Wu Y, Yu J and Li B: Age-dependent dopaminergic dysfunction following fetal exposure to atrazine in SD rats. Environ Toxicol Pharmacol 37: 1275-1282, 2014.

29. Whitmer AJ and Gotlib IH: Depressive rumination and the C957T polymorphism of the DRD2 gene. Cogn Affect Behav Neurosci 12: 741-747, 2012.

30. Chen C, Yang JM, Hu TT, Xu TJ, Xu WP and Wei W: Elevated dopamine D2 receptor in prefrontal cortex of CUMS rats is associated with downregulated cAMP-independent signaling pathway. Can J Physiol Pharmacol 91: 750-758, 2013. 
31. Goldstein DS, Sullivan P, Holmes C, Kopin IJ, Sharabi Y and Mash DC: Decreased vesicular storage and aldehyde dehydrogenase activity in multiple system atrophy. Parkinsonism Relat Disord 21: 567-572, 2015.

32. Klimek V, Stockmeier C, Overholser J, Meltzer HY, Kalka S, Dilley G and Ordway GA: Reduced levels of norepinephrine transporters in the locus coeruleus in major depression. J Neurosci 17: 8451-8458, 1997.

33. Kanetani K, Kimura M and Endo S: Therapeutic effects of milnacipran (serotonin noradrenalin reuptake inhibitor) on depression following mild and moderate traumatic brain injury. J Nippon Med Sch 70: 313-320, 2003.

34. Mössner R, Mikova O, Koutsilieri E, Saoud M, Ehlis AC, Müller N, Fallgatter AJ and Riederer P: Consensus paper of the WFSBP task force on biological markers: Biological markers in depression. World J Biol Psychiatry 8: 141-174, 2007.
35. Artigas F: Developments in the field of antidepressants, where do we go now? Eur Neuropsychopharmacol 25: 657-670, 2015.

36. Butini S, Gemma S, Campiani G, Franceschini S, Trotta F, Borriello M, Ceres N, Ros S, Coccone SS, Bernetti M, et al: Discovery of a new class of potential multifunctional atypical antipsychotic agents targeting dopamine D3 and serotonin 5-HT1A and 5-HT2A receptors: Design, synthesis and effects on behavior. J Med Chem 52: 151-169, 2009.

37. Pehek EA, McFarlane HG, Maguschak K, Price B and Pluto CP: M100,907, a selective 5-HT (2A) antagonist, attenuates dopamine release in the rat medial prefrontal cortex. Brain Res 888: $51-59,2001$ 